\title{
AVALIAÇÃO FÍSICA DOS ALUNOS QUE INGRESSAM NAS ACADEMIAS DE GINÁSTICA DE ITAPETININGA - SP
}

\section{ARTIGO ORIGINAL}

NASCIMENTO, Marcelo Victor Rodrigues do ${ }^{1}$

NASCIMENTO, Marcelo Victor Rodrigues do. Avaliação física dos alunos que ingressam nas academias de ginástica de Itapetininga - SP. Revista Científica Multidisciplinar Núcleo do Conhecimento. Ano 04, Ed. 10, Vol. 05, pp. 84-103. Outubro de 2019.

ISSN: 2448-0959,

Link de acesso: https://www.nucleodoconhecimento.com.br/educacao-fisica/academias-deginastica

\section{RESUMO}

Este trabalho teve por objetivo verificar como é tratada a questão da avaliação física dos alunos que ingressam nas academias de ginástica do Município de Itapetininga, ou seja, se ela é realizada, quais avaliações são feitas, a periodicidade com que elas são repetidas e o grau de importância que as academias dão ao processo de avaliação física. Para tanto, foram entrevistadas 31 (trinta e uma) academias de ginástica e 4 (quatro) clubes que possuem academia de ginástica. Na entrevista, foi abordado (1) a forma como cada academia realiza a avaliação física dos novos alunos; (2) o tipo de avaliação que é realizado; (3) a periodicidade das avaliações físicas; e (4) o grau de importância que cada academia tributa à avaliação física dos alunos. Quanto à forma

\footnotetext{
${ }^{1}$ Acadêmico do Mestrado em Treino Desportivo, pela Escola Superior de Desporto e Lazer (ESDL), do Instituto Politécnico de Viana do Castelo (IPVC) Melgaço/Portugal.Especialista em Exercícios Resistidos na Saúde, na Doença e no Envelhecimento, pela Faculdade de Medicina da Universidade de São Paulo (USP).Pós-graduado em Fisiologia do Exercício, pela Escola Paulista de Medicina.Bacharel em Educação Física, pela Escola de Educação Física do Exército (ESEFEX), no Rio de Janeiro.
} 
de realização da avaliação física, os três maiores percentuais foram: $57 \%$ exigem apresentação de atestado médico, 34\% realizam avaliação com profissionais da própria academia e 14\% aceitam declaração verbal/escrita do próprio aluno. Quanto ao tipo de avaliação realizada por aquelas que possuem profissionais capacitados para fazê-lo, os resultados mostraram que (1) 92\% realizam anamnese; (2) 66\% realizam avaliação postural; (3) $66 \%$ colhem medidas antropométricas; (4) 33\% aplicam testes físicos e funcionais; e (5) 17\% aplicam a bioimpedância. Quanto á periodicidade das avaliações, os resultados mostraram que (1) uma academia não repete a avaliação física inicial; (2) uma academia repete a avaliação apenas quando o aluno solicita; (3) três academias repetem a avaliação de acordo com a necessidade do aluno; (4) duas academias repetem a avaliação mensalmente; (5) uma academia repete a avaliação bimestralmente; e (6) quatro academias repetem a avaliação trimestralmente. Quanto ao grau de importância dado às avaliações, os resultados mostraram que (1) $60 \%$ atribuíram o grau "fundamental"; (2) 31\% atribuíram o grau "importante"; (3) nenhuma academia atribuiu o grau "pouco importante"; e (4) $9 \%$ atribuíram o grau "indiferente". Conclui-se que o processo de avaliação física inicial nas academias de ginástica de Itapetininga ainda necessita ser entendido e valorizado como algo fundamental e imprescindível para a prática consciente e responsável do exercício físico por parte dos próprios profissionais de educação física.

Palavras-chave: academia de ginástica, avaliação física, profissionais de educação física.

\section{INTRODUÇÃO}

Nas últimas décadas, embora a revolução tecnológica tenha trazido uma mudança no estilo de vida das pessoas, levando ao aumento da inatividade pelas facilidades que proporcionou (uso de automóvel, escada rolante, elevadores, vídeo game, televisão, computadores, etc.), tem-se observado, em contrapartida, que a prática de atividade física também vem ganhando uma posição de destaque na sociedade brasileira (Homrich, 2013). 
O número de academias de ginástica tem crescido vertiginosamente no país, com uma melhora expressiva nos serviços por elas oferecidos, os quais, via de regra, são realizados de forma orientada por um número cada vez maior de profissionais diplomados nas diversas faculdades de educação física espalhadas pelo Brasil (Cazón e Melo, 2010).

Além da prevenção de doenças, da promoção de saúde e da melhora da qualidade de vida, há outras razões que tem impulsionado as pessoas a procurarem as academias de ginástica, tais como o "emagrecimento" e a "estética corporal" (Prestes, Moura e Hopf, 2002, p. 3).

Tais aspectos motivacionais, pelas suas próprias características, requerem avaliação física periódica, tornando alguns indicadores, como "peso", "circunferências corporais" e "índice de massa corporal", instrumentos indispensáveis para os educadores físicos quantificarem as variáveis de treino e controlarem os resultados (Cazón et al., 2010).

É comum as pessoas associarem avaliação física com uma grande quantidade de aparelhos de difícil acesso e de alto custo; porém, na prática, o que se observa é que, com um pequeno número de equipamentos de baixo custo operacional, é possível realizar uma triagem inicial de qualidade, aplicando-se inicialmente um simples questionário, e, se necessário, encaminhando o aluno para a realização de exames mais sofisticados (Carvalho, Nobrega, Lazzoli, Magni, Rezende, Drumond, Oliveira et al., 1996).

Ainda assim, mesmo que as avaliações sejam pouco dispendiosas e relativamente fáceis de se executar, algumas pesquisas mostram que há um grande número de academias que não as realizam, expondo seus alunos à prática de atividades físicas sem qualquer parâmetro inicial do estado de saúde dos mesmos (Cazón et al., 2010).

De acordo com Schwaab (2015), a falta de parâmetros do estado de saúde pode influenciar negativamente nas respostas ao treinamento; além do que pode representar uma ameaça potencial para pessoas portadoras de problemas 
cardiovasculares, fazendo, da avaliação física, em alguns casos, uma questão de vida ou morte.

A literatura comprova que somente uma avaliação do estado de saúde poderá esclarecer as características individuais e, portanto, permitir que determinado programa de exercícios seja realmente o mais indicado para cada um, reduzindo assim a probabilidade de: se obter resultados abaixo do esperado, não se promover resultado algum, ou, até mesmo, causar algum dano ao praticante (Pires, 2010, citado por Homrich, 2013).

Reconhecendo essas verdades científicas, o Conselho Federal de Educação Física (CONFEF), órgão que tem o poder delegado pela União para normatizar, orientar, disciplinar e fiscalizar o exercício da profissão de educador físico e das academias de ginástica, emitiu, em 07 de julho de 2012, a Nota Técnica 002/2012, que trata da avaliação física em programas de exercícios físicos e desportivos.

Em tal Nota Técnica, o CONFEF reconheceu, em linhas gerais, que:

- É competência e atribuição do educador físico realizar as avaliações físicas;

- A avaliação física é uma ferramenta essencial para o trabalho do educador físico;

- A avaliação física deve ser ampla e sistemática, devendo ser elaborada de acordo com os objetivos e as características do beneficiário;

- A avaliação física pode ser composta por anamnese completa, análise dos fatores de risco para coronariopatia, classificação de risco, verificação dos principais sintomas ou sinais sugestivos de doença cardiovascular e pulmonar, medidas antropométricas, testes neuromotores, avaliação metabólica, avaliação cardiorrespiratória e avaliação postural;

- A exigência de atestado médico (indispensável para a prática de atividades físicas) não garante a segurança pretendida para o beneficiário e não exime o educador físico das suas responsabilidades quanto à prescrição e orientação do exercício físico e esportivo (Nota Técnica 002/2012, 2012); 
Mediante tal parecer técnico, o CONFEF baixou as seguintes diretrizes para a realização das avaliações físicas dos alunos das academias de ginástica:

- Antes do início do desenvolvimento do programa de exercícios, o educador físico deverá realizar avaliação física de acordo com a sua respectiva área de intervenção;

- O educador físico deverá solicitar avaliação médica especializada caso identifique quaisquer fatores de risco para o aluno que podem ser agravadas pela atividade física;

- A aplicação dos testes deve ser feita baseada nos conhecimentos adquiridos na capacitação profissional;

- Os dados a serem coletados nas avaliações incluem prontidão para a atividade física, fatores de risco, qualidade de vida e nível de atividade física;

- O educador físico deve aferir e avaliar pressão arterial e frequência cardíaca, aplicar escalas de percepção do esforço, utilizar ergômetros (esteira, cicloergômetro, etc.) e outros equipamentos utilizados em programas de atividade física, utilizar equipamentos para medição de glicemia e concentração de lactatos, interpretar os resultados obtidos, realizar e interpretar avaliação de medidas antropométricas e testes de percepção de esforço;

- No âmbito da avaliação física, o educador físico poderá trabalhar individualmente ou em equipes multiprofissionais;

- O educador físico deverá registrar as informações relativas à avaliação física, contendo informações como dados pessoais, hábitos de vida, uso ou não de medicamentos, tratamento médico específico, limitações físicas, condições físicas e programa desenvolvido pelo beneficiário, mantendo-os sob sigilo profissional (Nota Técnica 002/2012, 2012).

Assim sendo, este trabalho tem por objetivo verificar se as academias de ginástica do município de Itapetininga realizam avaliação física dos alunos que começam a frequentá-las, quais avaliações são realizadas, a periodicidade com que são repetidas e o grau de importância que as mesmas dão ao processo de avaliação física. 


\section{METODOLOGIA}

Conforme definições de Cervo e Bervian (1983), esta pesquisa pode ser classificada como um estudo descritivo e transversal, destinado a observar, registrar, analisar e correlacionar fenômenos (variáveis), sem manipulá-los, ocorridos em um dado momento, com um público específico, sem se preocupar com causas e efeitos.

O instrumento de coleta foi um questionário elaborado pelo autor deste artigo, contendo 5 (cinco) perguntas objetivas, respondidas pelo público-alvo no período de 15 a 25 de setembro de 2019.

\section{- Amostra}

A amostra analisada na investigação foi constituída por 31 (trinta e uma) academias de ginástica e 4 (quatro) clubes que possuem academia de ginástica, todos do Município de Itapetininga - SP, cujos responsáveis/funcionários, após terem tomado conhecimento, manifestaram interesse em participar do estudo.

No que se refere às academias, o Guia das Empresas de Itapetininga de 2019 apresenta um total de 31 (trinta e uma) academias, das quais 1 (uma) não foi entrevistada e 3 (três) encontram-se fechadas. Entretanto, 4 (quatro) novas academias de ginástica foram abertas na cidade, as quais possivelmente farão parte da edição de 2020 do referido guia, perfazendo um total de 31 (trinta e uma) academias entrevistadas (Guia das Empresas, 2019).

Quanto aos clubes, o referido guia apresenta 8 (oito) clubes, porém apenas 4 (quatro) deles possuem academias de ginástica, as quais fizeram parte da pesquisa.

Dessa forma, este estudo abrangeu aproximadamente $100 \%$ do público-alvo, o qual, para efeitos deste trabalho, será cognominado doravante de "academias de ginástica". 
- Procedimentos

O questionário constante da Tabela 01 (abaixo) foi apresentado aos responsáveis/funcionários das academias de ginástica do Município de Itapetininga $\mathrm{SP}$, os quais preencheram-no na presença do autor da pesquisa.

Os dados coletados foram tratados quantitativamente, empregando-se as variáveis estatísticas "percentual", "valor mínimo" e "valor máximo".

Tabela 1. Questionário para os professores (Questionnaire for teachers).

\section{Questionário}

1. Como é feita a avaliação física do aluno que ingressa na academia?

A academia realiza avaliação física com profissionais próprios.

A academia exige apresentação de atestado médico.

A academia aceita a declaração verbal/escrita do aluno.

Não há avaliação física do aluno para ingresso.

Outra forma. Qual?

2. Se a academia realiza avaliação física para ingresso, que tipo de avaliação é realizada?

Anamnese.

Avaliação Postural.

Medidas Antropométricas.

Testes Físicos (Teste de uma Repetição Máxima, Flexiteste, VO2 max)

Outro. Qual?

3. Quando realizada, a avaliação física inicial é repetida periodicamente?

\section{( ) Sim ( ) Não}

4. Quando realizada, de quando em quando a avaliação física é repetida?

1 (um) mês

2 (dois) meses

3 (três) meses

4 (quatro) meses 
6 (seis) meses

1 (um) ano

A pedido do aluno

Outro período. Qual?

5. Que grau de importância a academia dá para a avaliação física dos alunos?

Fundamental

Importante

Pouco importante

Indiferente (o aluno é responsável por si)

\section{ANÁLISE E DISCUSSÃO DOS DADOS}

Com a utilização de uma entrevista estruturada, na qual o entrevistado poderia assinalar mais de uma resposta para a primeira e segunda perguntas, abriu-se a possibilidade de que houvesse mais respostas do que o número total de academias de ginástica; o que de fato ocorreu, pois, das que realizam avaliação física nos novos alunos, 6 (seis) delas afirmaram aplicar mais de uma forma de avaliação.

\section{- Primeira pergunta}

As respostas para a primeira pergunta do questionário (especificado na Tabela 1), indicaram os seguintes percentuais, visualizados graficamente na Figura 1:

- $34 \%$ realizam avaliação com profissionais da própria academia (12 academias);

- $57 \%$ exigem apresentação de atestado médico (20 academias);

- $14 \%$ aceitam declaração verbal/escrita do próprio aluno (5 academias);

- $9 \%$ não realizam avaliação física (3 academias); e

- $3 \%$ apresentam outra forma de avaliar fisicamente os novos alunos (1 academia). 
Figura 1. Gráfico demonstrativo de como é feita a avaliação física dos alunos que ingressam na academia (Graphic demonstrating how the physical evaluation of students entering the gym is made).

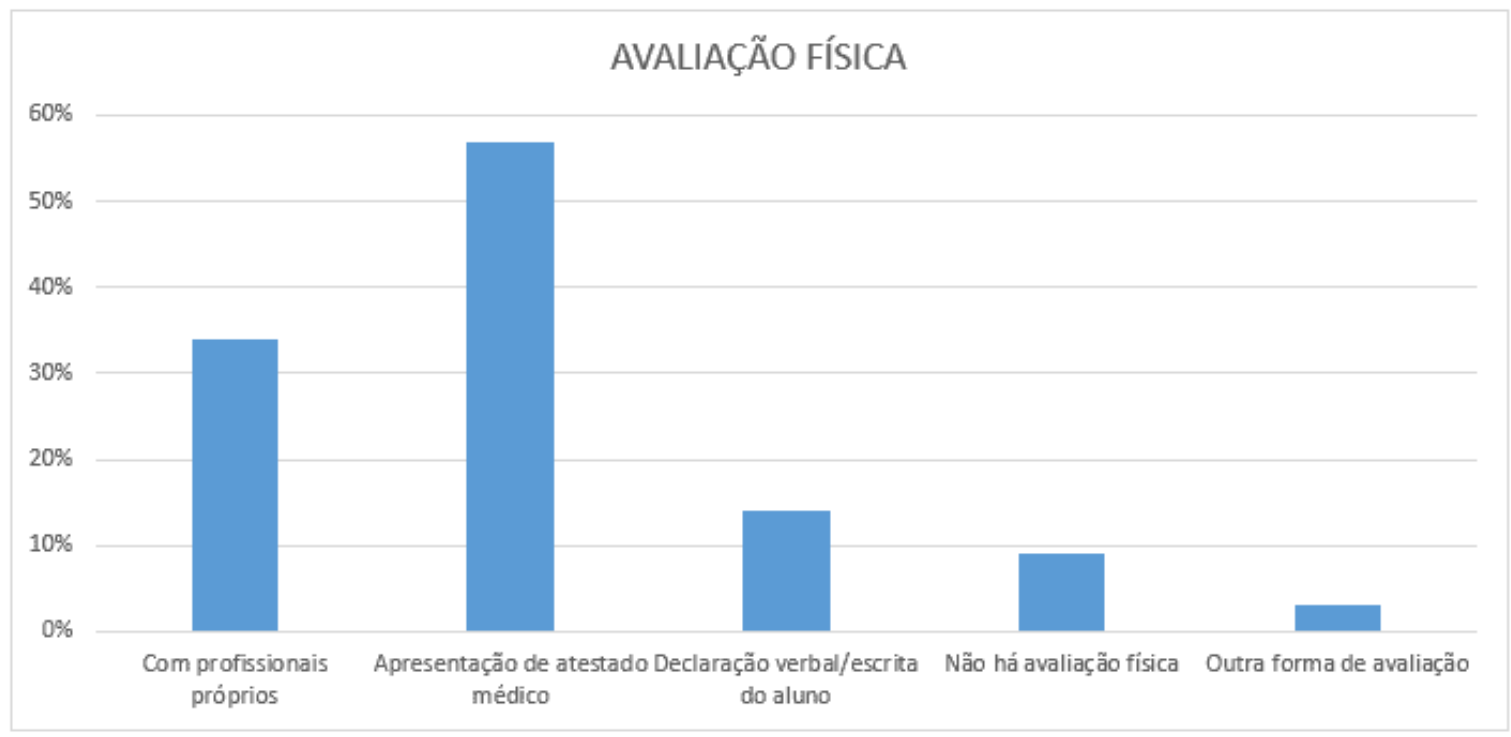

Fonte: autor.

Numa primeira análise, percebe-se que, das 35 (trinta e cinco) academias entrevistadas, apenas 3 (três) delas afirmaram não realizar qualquer tipo de avaliação nos novos alunos, ignorando completamente o estado de saúde dos mesmos, algo fundamental para todo e qualquer programa de exercícios físicos (Sanches, 2008).

Dos 34\% das academias de ginástica que realizam avaliação física com profissionais da própria academia, 55\% delas realizam exclusivamente essa forma de avaliação e $45 \%$ incluem também a exigência de atestado médico, procedimento que se encaixa nas diretrizes do American College of Sport Medicine (ACSM) para avaliação física e está de acordo com a legislação em vigor no Brasil (ACSM, 2014; Lei oํ 10.848, 2001; Lei oㅜ 16.724, 2018; Nota Técnica 002/2012, 2012).

Dos $57 \%$ das academias de ginástica que exigem apresentação de atestado médico, $75 \%$ delas usam exclusivamente essa forma de avaliação física, o que é bom apenas com relação ao cumprimento da legislação em vigor. O restante delas $(25 \%)$ inclui a 
realização de avaliação física com profissionais próprios, usufruindo de informações imprescindíveis para elaboração de um programa de treino (Sanches, 2008).

Dos $14 \%$ das academias de ginástica que aceitam a declaração verbal/escrita dos alunos, nenhuma delas realiza outro tipo de avaliação física, deixando de contar com dados importantes sobre o estado de saúde dos alunos e de observar a legislação em vigor (Lei no 10.848, 2001; Lei no 16.724, 2018; Nota Técnica 002/2012, 2012).

Já a única academia de ginástica que afirmou realizar "outra forma de avaliação" (exame de bioimpedância), o faz somente em adolescentes e idosos, excluindo os novos alunos adultos, os quais são a grande maioria dos praticantes de atividade física em academias (Vilela e Rombaldi, 2015, p. 209).

Assim sendo, somando-se os percentuais de academias que aceitam declaração verbal/escrita do aluno, que não realizam avaliação física para ingresso e que realizam outra forma de avaliação, é possível perceber que $26 \%$ das academias de ginástica prestam seus serviços sem que haja um controle efetivo sobre o estado de saúde dos praticantes e descumprindo a lei.

Quanto às academias que atendem a determinação legal e solicitam atestado médico para os novos alunos (Lei no 10.848, 2001; Lei no 16.724, 2018; Nota Técnica 002/2012, 2012), percebe-se que há uma deficiência quanto a mensuração da evolução do treino, faltando-Ihes dados concretos que permitam fazê-lo, com exceção daquelas que complementam a avaliação utilizando seus profissionais $(25 \%)$.

Dessa forma, caso somemos os $26 \%$ de academias que não controlam efetivamente o estado de saúde dos alunos que ingressam, com as academias que exigem apenas atestado médico para a prática de atividade física, teremos um universo considerável de profissionais que atuam sem seguir critérios científicos no tocante ao planejamento de treino para seus alunos, e que, portanto, realizam seus trabalhos de forma empírica, conforme tem sido relatado em outras pesquisas (Cazón et al., 2010, p. 1). Além disso, as academias que não controlam efetivamente o estado de saúde dos 
alunos trabalham á margem da lei, negligenciado o fato de que o atestado médico é importante para detectar riscos de doença cardiovascular (ACSM, 2014).

Das 35 (trinta e cinco) academias entrevistadas, somente uma mostrou fazer diferenciação na avaliação física dos alunos quanto à idade, respeitando a Lei no 16.724, cujo Artigo $5^{\circ}$ diz o seguinte: "As matrículas para frequentar os estabelecimentos de que trata esta lei dependem:

I - para os interessados com idade entre 15 e 69 anos, da resposta ao Questionário de Prontidão para Atividade Física (PAR-Q) que consta do Anexo I desta lei;

II - para os interessados com idade inferior a 15 anos, de autorização por escrito de pai ou responsável;

III - para os interessados com idade a partir de 70 anos, de apresentação de atestado de aptidão para prática de atividade física, do qual deverá constar, obrigatoriamente, o nome completo do médico, seu número no Conselho Regional de Medicina - CRM e eventuais observações relativas às especificidades de cada caso concreto" (Lei ${ }^{\circ}$ $16.724,2018)$.

- Segunda pergunta

Segundo Cazón et al. (2010), a literatura sugere que sejam obedecidas as seguintes etapas para uma avaliação física eficaz, suficiente para identificar o estado inicial do aluno e orientar o trabalho do professor:

- Questionário de verificação da saúde (PAR-Q), que pode ser substituído por atestado médico;

- Questionário com aspectos pessoais (anamnese);

- Avaliação da composição corporal (antropometria); e

- Testes de forças e funcionais. 
Dessa forma, com relação à segunda pergunta, referente ao tipo de avaliação física realizada pelas academias, as respostas apresentaram os seguintes percentuais, visualizados graficamente na Figura 2:

- $92 \%$ realizam anamnese;

- $66 \%$ realizam avaliação postural;

- $66 \%$ colhem medidas antropométricas;

- $33 \%$ aplicam testes físicos e funcionais; $\mathrm{e}$

- $17 \%$ aplicam a bioimpedância.

Figura 2. Gráfico demonstrativo do tipo de avaliação realizada pelas academias (Chart showing the type of assessment performed by the gyms).

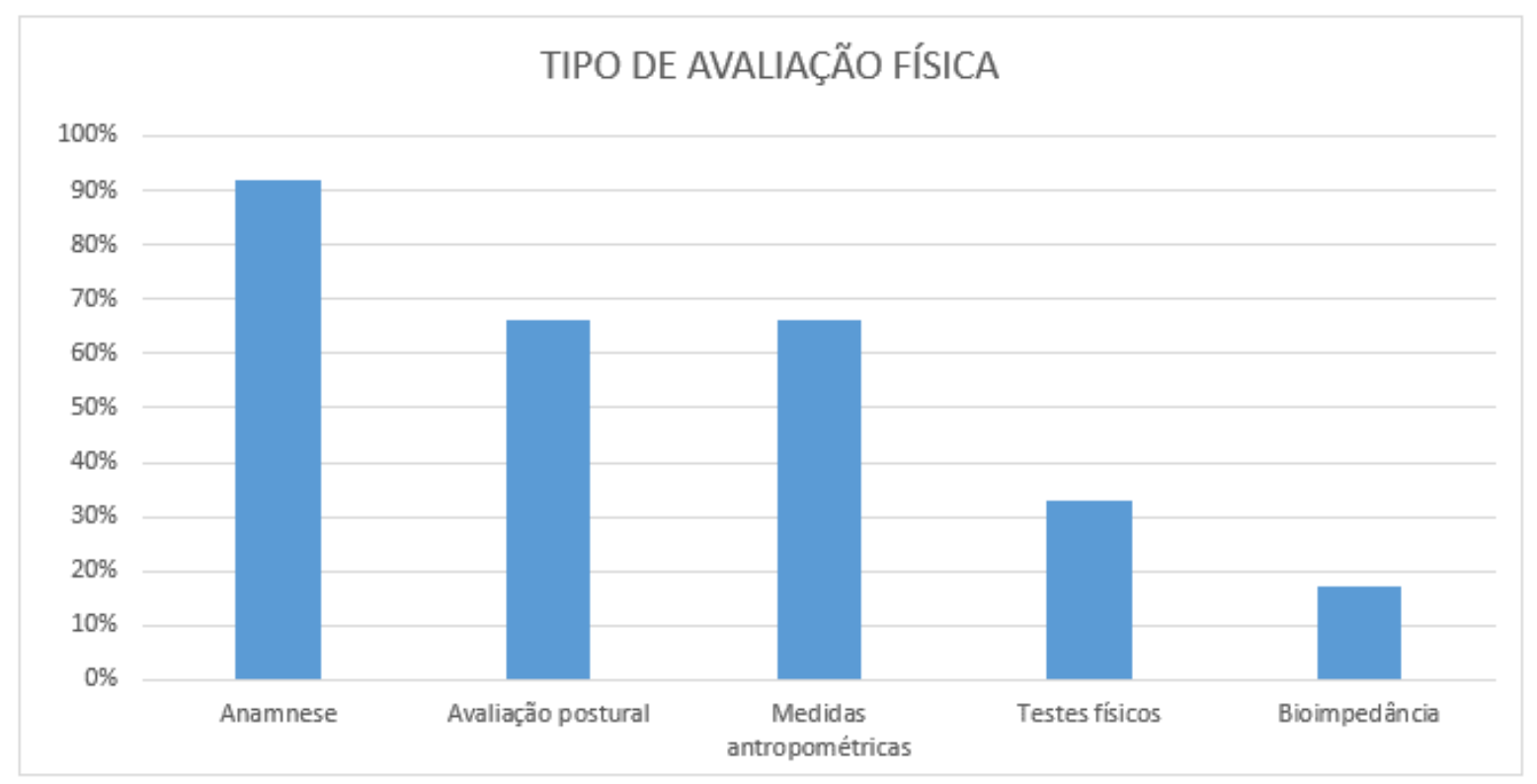

Fonte: autor.

Diante desses percentuais, percebe-se que, das academias que realizam avaliação física com profissionais próprios, uma delas abstêm-se de realizar a anamnese, deixando, portanto, de desfrutar de informações relacionadas a identidade da pessoa, seus hábitos, histórico clínico, histórico familiar e nível de atividade física (ACSM, 2014). 
Tal academia também não exige a apresentação de atestado médico, de sorte que, apesar de realizar avaliação física com profissionais, há uma condição de risco para os alunos por falta de informações fundamentais sobre os seus estados de saúde.

Quanto à avaliação postural, apenas $66 \%$ das academias que realizam a avaliação física dos alunos recém-chegados preocupam-se em observar se existem desequilíbrios posturais, podendo desenvolver um programa de treino voltado para reestruturação completa das cadeias musculares comprometidas (Verderi, 2013, p. 1). Já os $44 \%$ restantes terminam por desprezar essas informações importantes para promover saúde e qualidade de vida.

No tocante às medidas antropométricas, verifica-se que apenas $66 \%$ das academias possuem um controle efetivo desses dados (peso, altura, circunferência de cintura, circunferência de quadril, dobras cutâneas, diâmetros e perímetros), os quais estão relacionados ao estado nutricional (desnutrição, excesso de peso e obesidade) e servem para avaliação de riscos para algumas doenças, tais como: diabetes mellitus, cardiopatias e hipertensão arterial sistêmica, tanto em adultos como em idosos (Sanches, 2008).

Com relação aos testes físicos, das 12 (doze) academias que realizam avaliação com profissionais próprios, somente 4 (quatro) delas adotam os referidos testes para estruturar e controlar o treino. As demais ignoram sua eficácia no acompanhamento do desempenho dos alunos, na identificação das limitações, tais como articulares e de flexibilidade, e em proporcionar maior segurança na realização dos exercícios (ACMS, 2014).

\section{- Terceira pergunta}

Das 12 (doze) academias que realizam avaliação com profissionais próprios, apenas uma delas afirmou não repetir a avaliação inicial; de sorte que, no caso dessa academia, o acompanhamento do progresso do treino encontra-se prejudicado, tornando inútil, nesse aspecto, a própria avaliação inicial. 
- Quarta pergunta

Quanto à periodicidade da avaliação física, preconizada pela literatura (Bojarczuk, 2002, p. 11), uma das academias que exige a apresentação de atestado médico, o faz anualmente; já a academia que realiza bioimpedância somente em idosos e adolescentes, o faz mensalmente; e das 12 (doze) academias que realizam avaliação com profissionais próprios, foram apresentados os seguintes dados:

- 1 (uma) academia não repete a avaliação física inicial;

- 1 (uma) academia repete a avaliação apenas quando o aluno solicita;

- 3 (três) academias repetem a avaliação de acordo com a necessidade do aluno;

- 2 (duas) academias repetem a avaliação mensalmente;

- 1 (uma) academia repete a avaliação bimestralmente; e

- 4 (quatro) academias repetem a avaliação trimestralmente.

Tais dados revelam que não há padronização quanto à periodicidade de aplicação da avaliação física dos alunos e que as avaliações trimestrais são as mais realizadas, o que parece estar de acordo com os manuais de fisiologia que apontam um período de 8 a 12 semanas para ocorrem mudanças corporais significativas para os treinos com exercícios resistidos, os mais procurados nas academias (Williams, Groves e Thurgood, 2010).

- Quinta pergunta

Quanto ao grau de importância que as academias dão à avaliação física dos novos alunos, o resultado das entrevistas apresentou o seguinte percentual, expressado graficamente na Figura 3:

- $60 \%$ atribuíram o grau "fundamental" (21 academias);

- $31 \%$ atribuíram o grau "importante" (11 academias);

- $0 \%$ atribuíram o grau "pouco importante"; e

- $9 \%$ atribuíram o grau "indiferente" (3 academias). 
Figura 3. Gráfico demonstrativo do grau de importância atribuído pelas academias à avaliação física (Graph showing the degree of importance attributed by the gyms to the physical evaluation).

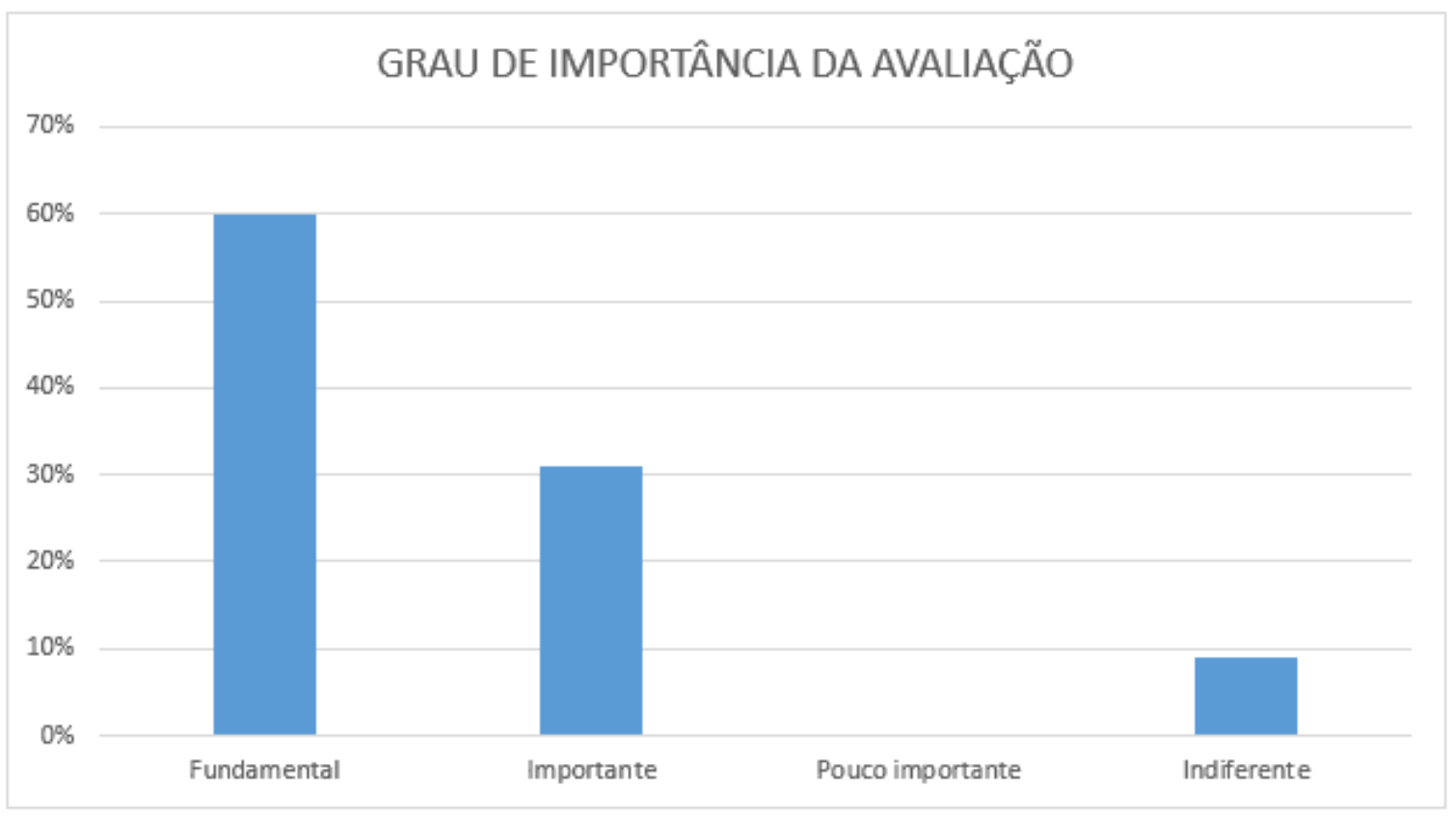

Fonte: autor.

Das 21 (vinte e uma) academias que realizam avaliações com profissionais próprios, 18 (dezoito) delas atribuíram o grau "fundamental" para a avaliação física dos novatos, o que era de se esperar, pois elas preocupam-se em realizar tais avaliações.

Das 11 (onze) academias que atribuíram grau "importante", 6 (seis) delas exigem atestado médico dos alunos novatos, 4 (quatro) aceitam declaração verbal/escrita do aluno e 1 (uma) aplica avaliação com profissionais próprios.

Entre as academias que não realizam qualquer avaliação física ( 3 academias), duas delas atribuíram, de forma coerente, o grau de importância "indiferente" para essa pergunta. Somou-se a elas uma das academias que exige apenas atestado médico para os novos alunos e que não realiza avaliação com profissionais próprios. 


\section{CONCLUSÕES}

Os números colhidos na pesquisa mostram que o processo de avaliação física inicial nas academias de ginástica de Itapetininga ainda necessita ser entendido e valorizado como algo fundamental e imprescindível para a prática consciente e responsável do exercício físico, por parte dos próprios profissionais de educação física (Homrich, 2013).

Os dados coletados na avaliação física são a fonte real e concreta para o planejamento e prescrição dos exercícios, adequando-se tipo, volume e intensidade de treino ao nível de saúde do praticante, de forma a atingir os objetivos propostos, sem lesões e riscos para a saúde (Bojarczuck, 2002).

Ao deixar de realizar avaliação, grande parte dos profissionais de educação física entrevistados mostram que estão trabalhando de forma empírica, desprezando informações científicas importantíssimas que podem auxiliá-los no gerenciamento e ministração do treino (Heyward, 2004).

O acompanhamento da evolução do treino e a percepção se os objetivos propostos inicialmente estão sendo atingidos são fatores importantes que também estão prejudicados pela não realização de avaliação nas academias entrevistadas (Sanches, 2008). Segundo Feijó (1992), tais parâmetros possuem um forte componente motivacional que reflete na continuidade do programa de treino, de sorte que, ao não serem utilizados, as academias acabam por dificultar a adesão do aluno e favorecem o abandono do programa.

Diversos trabalhos ligados à área motivacional têm mostrado que é significativo o número de pessoas que procuram as academias de ginástica em busca de reduzir peso (emagrecimento) e melhorar a estética corporal (Liz, Crocetta, Viana, Brandt e Andrade, 2010); de sorte que, ao deixar de controlar os dados antropométricos, como ocorre em diversas academias entrevistadas, perde-se a oportunidade de motivar seus alunos, correndo o risco de favorecer a evasão. 
As medidas antropométricas, além do aspecto motivacional, revelam o estado nutricional da pessoa, sendo fundamental para corrigir hábitos nutricionais incorretos, estabelecer condutas clínicas e prescrever exercícios físicos adequados, garantindo um estado de saúde adequado em todas as etapas da vida (Nacif e Vierng, 2011). Tais medidas são importantes para se verificar a saúde, a normalidade e a capacidade funcional do indivíduo, desde que seja dado significado a elas, a fim de que o educador físico possa tomar decisões de acordo com padrões estabelecidos cientificamente (Sanches, 2008).

Quando se utiliza apenas o atestado médico como forma de avaliar fisicamente os alunos, como ocorre em grande parte das academias entrevistadas (57\%), perde-se um parâmetro importante para mensurar a evolução do treino, ainda que a academia esteja cumprindo um dispositivo legal (Lei no 10.848, 2001; Lei oㅜ 16.724, 2018; Nota Técnica 002/2012, 2012).

Percebe-se que não há padronização quanto a avaliação física dos alunos nas academias entrevistadas, não só quanto à forma, mas também quanto à periodicidade das avaliações, dificultando, assim, o controle dos resultados e a personalização do trabalho, algo que, quando corretamente empregado, exerce forte influência positiva (Oliveira, Silva e Toscano, 2014).

Do ponto de vista legal, grande parte das academias necessita rever seus conceitos para se enquadrar nos dispositivos fixados pelo ordenamento jurídico, o qual tem a atividade física como determinante e condicionante da saúde (Lei oㅜ 12.864, 2013), dando especial atenção ao aspecto da idade dos praticantes (Lei oㅜ 16.724, 2018) e às resoluções do CONFEF (Nota Técnica 002/2012).

\section{REFERÊNCIAS}

AMERICAN COLLEGE OF SPORT MEDICINE (ACMS). Diretrizes da ACMS para os Testes de Esforço e sua Prescrição. Rio de Janeiro: Guanabara Koogan, 2014. 
BRASIL. Lei no 12.864, de 24 de setembro de 2013. Diário Oficial [da] União, Poder Executivo, Brasília, DF, 25 set. 2013. Seção 1, p. 5.

BOJARCZUK, Tatiana. Avaliação Física: Estruturando suas Premissas Básicas em Academias. Trabalho de Conclusão de Curso. Faculdade de Educação Física da Universidade Estadual de Campinas, Campinas, 2002.

CARVALHO, T.; NOBREGA, A.C.L.; LAZZOLI, J.K.; MAGNI, J.R.T.; REZENDE, L.; DRUMOND, F.A.; OLIVEIRA, M.A.B. et al. Posição Oficial da Sociedade Brasileira de Medicina do Esporte: atividade física e saúde. Revista Brasileira de Medicina do Esporte, Niterói, v. 2, n. 4, p. 79-81, out./dez. 1996.

CAZÓN, R.L.; MELO, M.F. Utilização de avaliação física nas academias de Planaltina, DF. Revista Digital, Buenos Aires, ano 14, n. 142, mar. 2010. Disponível em: $\quad$ <https://www.efdeportes.com/efd142/utilizacao-de-avaliacao-fisica-nasacademias.htm>. Acesso em: 25 set. 2019.

CERVO, Amado Luiz; BERVIAN, Pedro Alcino. Metodologia científica. 3. ed. São Paulo: Prentice Hall, 1983.

FEIJÓ, O.G. Corpo e movimento: uma psicologia para o esporte. Rio de Janeiro: Shap, 1992.

GUIA DAS EMPRESAS. Itapetininga: AZfoto, 2019.

HEYWARD, Vivian $H$. Avaliação física e prescrição de exercício: técnicas avançadas. 4. ed. Porto Alegre: Artmed, 2004.

HOMRICH, Luciana Marotto (org.). Avaliação física. Brasília: Fundação Vale, 2013.

LIZ, C.M.; CROCETA, T.B.; VIANA, M.S.; BRANDT, R.; ANDRADE, A. Aderência à prática de exercícios físicos em academias de ginástica. Revista Motriz, Rio Claro, v. 16 , n. 1 , p. $181-188$, jan./mar. 2010 
NACIF, M. A. L.; VIERNIG, R. F. Avaliação antropométrica no ciclo da vida: uma revisão prática. 2. ed. São Paulo: Metha, 2011.

NOTA TÉCNICA 002/2012. A avaliação física em programas de exercícios físicos e desportivos. Rio de Janeiro: CONFEF, jul. 2012.

OLIVEIRA, N.M; SILVA, D.A.S.; TOSCANO, J.J.O. Programas de avaliação em academias de ginástica: o que se faz? Revista Brasileira de Atividade Física e Saúde, Pelotas, v. 19, n. 5, p. 568-570, set. 2014.

PRESTES, M.T., MOURA, J.A.R., HOPF, A.C.O. Estudo exploratório sobre prescrição, orientação e avaliação de exercícios físicos em musculação. Revista Kinesis da Universidade Federal de Santa Maria, Santa Maria, n. 26, p. 22-166, mai. 2002.

RIKLI, R. E.; JONES, J. J. Development and validation of a functional fitness test for community-residing older adults. Journal of Aging and Physical Activity, v.7, n. 2, p. 129-161, april 1999.

SANCHES, Alcir Braga (coord.). Educação física a distância: Módulo 4. Brasília: Universidade de Brasília, 2008. 540 p.

SÃO PAULO (Estado). Lei no 10.848 , de 06 de julho de 2001. Dispõe sobre o registro e funcionamento de estabelecimentos de ensino e prática de modalidades esportivas. Diário Oficial do Estado de São Paulo, Poder Legislativo, São Paulo,SP, 7 de julho de 2001. v.111, n.127. p. 1.

SÃO PAULO (Estado). Lei no 16.724, de 22 de maio de 2018. Acrescenta o artigo $5^{\circ}$ A, altera o artigo $6^{\circ}$ e revoga o "caput" do artigo $5^{\circ}$ da Lei oㅜ 10.848, de 06 de julho de 2001. Diário Oficial do Estado de São Paulo, Poder Legislativo, São Paulo, 23 de maio de 2018, p. 5.

SCHWAAB, Fernanda. A influência da avaliação antropométrica na mudança do estilo de vida dos sujeitos praticantes de musculação. 2017. Trabalho de 
Conclusão de Curso de Bacharel-Universidade Regional do Noroeste do Estado do Rio Grande do Sul, ljuí, 2017.

VERDERI, Erica. A importância da avaliação postural. Revista Digital, Buenos Aires, ano 8, n. 57, fev. 2003. Disponível em: < https://www.efdeportes.com/efd57/postura.htm>. Acesso em: 25 set. 2019.

VILELA, G.F., ROMBALDI, A.J. Perfil dos frequentadores das academias de ginástica de um município do Rio Grande do Sul. Revista Brasileira de Promoção de Saúde, Fortaleza, v. 28, n. 2, p. 206-215, abr./jun. 2015.

WILLIAMS, L. GROVES, D., THURGOOD, G. Treinamento de Força. Barueri: Manole, 2010.

\section{ANEXO}

Table 1. Questionnaire for teachers.

\section{Questionnaire}

1. How is the physical assessment of the student who enters the gym?

The gym conducts physical evaluation with its own professionals..

The gym requires presentation of medical certificate.

The academy accepts the student's verbal / written statement.

There is no physical assessment of the student for admission.

Other way. Which?

2. If the academy performs physical assessment for admission, what type of assessment is performed?

Anamnesis.

Postural evaluation.

Anthropometric measurements.

Physical Tests (Maximum Repeat Test, Flexitest, VO2 max)

Other. Which

3. When performed, is an initial physical assessment periodically repeated? 


\section{( ) Yes ( ) No}

4. When performed, from time to time is the physical assessment repeated?

1 (one) month

2 (two) months

3 (three) months

4 (four) months

6 (six) months

1 (one) year

At student's request

Another period. Which?

5. How important is the academy to the physical assessment of students?

Elementary

Important

Little important

Indifferent (the student is responsible for themselves

Enviado: Outubro, 2019.

Aprovado: Outubro, 2019. 